\title{
EXTERNAL FIXATOR IMMOBILISED CROSS-LEG FLAP- OUR EXPERIENCE
}

\author{
Ramneesh Garg1, Sheerin Shah2, Sanjeev Uppal3, Rajinder Mittal', Bhavya Thakur ${ }^{5}$
}

${ }^{1}$ Associate Professor, Department of Plastic Surgery, DMC and Hospital, Ludhiana, Punjab, India. ${ }^{2}$ Assistant Professor, Department of Plastic Surgery, DMC and Hospital, Ludhiana, Punjab, India.

3 Professor \& Head, Department of Plastic Surgery, DMC and Hospital, Ludhiana, Punjab, India.

4 Professor, Department of Plastic Surgery, DMC and Hospital, Ludhiana, Punjab, India.

${ }^{5}$ Resident, Department of Plastic Surgery, DMC and Hospital, Ludhiana, Punjab, India.

\begin{tabular}{l}
\hline ABSTRACT \\
BACKGROUND \\
Soft tissue defects of distal third leg has always been a reconstructive challenge. Though free flaps are the first choice, cross-leg flap \\
is still the saviour in difficult non-reconstructable situations. This study was conducted to analyse the outcome of using external \\
fixator for immobilising cross-leg flaps.
\end{tabular}

\section{MATERIALS AND METHODS}

This was a retrospective descriptive study done on 42 patients over a period of 3 years starting from April 2015 to April 2018, in the Department of Plastic Surgery, Dayanand Medical College and Hospital, Ludhiana.

\section{RESULTS}

A total number of 42 patients (36 males) were included in this study. All patients sustained injury following road traffic accidents. Primary flap coverage (within 24 hours) was done along with orthopaedic intervention in 11 patients. 5 patients had marginal flap necrosis. All patients tolerated external fixator well and did not have pin site infection.

\section{CONCLUSION}

We recommend that all cross-leg flap patients should be immobilised with external fixator.

\section{KEY WORDS}

External Fixator, Cross-Leg Flap, Immobilisation.

HOW TO CITE THIS ARTICLE: Garg R, Shah S, Uppal S, et al. External fixator immobilised cross-leg flap- our experience. J. Evolution Med. Dent. Sci. 2018;7(32):3617-3619, DOI: 10.14260/jemds/2018/812

\section{BACKGROUND}

The cross-leg flap is a fasciocutaneous flap raised from opposite/ cross-leg and inset over the recipient leg. It is most commonly used for soft tissue defects over the distal third of leg, ankle or dorsum of foot. Though free flap remains the first choice for such defects[1] followed by locoregional flaps like reverse sural artery flap,[2] inferiorly based fasciocutaneous flaps ${ }^{[3]}$ and perforator flaps.[4] The cross-leg flap is a saviour in difficult situations, where microvascular expertise is not available or when the injury to the involved leg is of such magnitude that no local/ regional tissue is available for wound coverage. The main issue with cross-leg flap has been immobilisation. Traditionally, it was done with Plaster of Paris cast, the trend now is to stabilise with external fixators. In this study, we analyse the advantages and disadvantages of using external fixators for immobilising cross-leg flaps. The objective of this study was to find out the efficacy of using External Fixator as the only mode of immobilisation in patients who undergo cross-leg flap.

\section{MATERIALS AND METHODS}

This was a retrospective descriptive study done on 42 patients over a period of 3 years starting from April 2015 to

'Financial or Other Competing Interest': None.

Submission 17-04-2018, Peer Review 24-07-2018,

Acceptance 30-07-2018, Published 06-08-2018.

Corresponding Author:

Sheerin Shah,

HJ-103, BRS Nagar, Ludhiana, Punjab, India.

E-mail: sheerinkathpal@gmail.com

DOI: $10.14260 /$ jemds/2018/812

\section{(c) (i) $(9)$}

April 2018, in the Department of Plastic Surgery, Dayanand Medical College and Hospital, Ludhiana.

\section{The Inclusion Criteria were-}

a. Patient with soft tissue defect of distal third leg/ ankle or foot with exposed tendon, bone, neurovascular structure

b. Defect arising out of trauma.

c. Patient willing to sign consent form, which clearly mentioned the need for immobilisation for minimum of 3 weeks.

d. Patient who had no obvious choice of locoregional flap or failed free flap.

e. Patient with healthy uninjured opposite leg.

\section{The Exclusion Criteria were-}

a. Patient with known joint disease of knee/ foot.

b. Soft tissue defect arising out of removal of malignancy.

All the cases enrolled were following trauma. They were initially managed in the emergency department of the institute. Resuscitative measures including restoration of airway, control of bleeding and circulation were done as per the set protocols. The wound if any was thoroughly cleaned with copious amount of saline, povidone-iodine and dressed. After detailed history and examination, patient was subjected to radiological investigations which primarily included x-ray of the involved limb. CT angiography was done along with wherever there was suspicion of associated vascular injury. The decision regarding timing of cross-leg flap was made in consultation with the orthopaedic team and depending upon the associated fractures or vascular injury and wound condition. 


\section{Surgical Technique}

Once the wound was debrided, the requisite flap size was marked on the donor leg. Calf region was the usual donor site, though depending upon the requirement it could involve raising almost whole of the leg skin. Fascia was included in all cases and sural nerve had to be sacrificed in cases where flap extended into distal half of leg. The flap was raised as a random pattern flap, $2.5 \mathrm{~cm}$ from the medial edge of tibia and not going beyond width-to-length ratio of $1: 2.5$. Once the flap was raised, donor site was covered with split skin graft and dressed. After the flap inset, the limb position was maintained by external fixation with the help of pins placed along anteromedial aspect of tibia (done by orthopaedic team). All the patients received post-operative antibiotics, analgesics and limb position checked regularly.

\section{RESULTS}

The present study was done over 3 years in the Department of Plastic Surgery, Dayanand Medical College and Hospital, Ludhiana. It is a premier tertiary care institute of North India, and is high volume centre for trauma patients. The present study included 42 patients, in the age range of 15 to 72 years, 36 males and 6 females. All patients were of Road traffic accidents with 7 patients on 4 wheelers, while 35 on 2 wheelers. 36 patients had associated fracture of either tibia (29) or both tibia and fibula (7) Table 1.

\begin{tabular}{|c|c|c|}
\hline Sl. No. & Particulars & No. \\
\hline 1 & No. of patients & 42 \\
\hline 2 & Mean age & 41.5 \\
\hline 3 & 2-wheeler injury & 35 \\
\hline 4 & 4-wheeler injury & 7 \\
\hline 5 & Associated tibia fracture & 29 \\
\hline 6 & Associated both bone fracture & 7 \\
\hline \multicolumn{2}{|c|}{ Table 1. Description of Patient's Epidemiology } \\
and Mode of Injury \\
\hline
\end{tabular}

11 patients underwent flap cover within 24 hours of sustaining trauma (Primary), 5 patients underwent flap cover after 24 hours but within one week of injury, while 26 patients underwent flap cover after one week of trauma. All patients with vascular injury underwent flap cover as the primary procedure. 5 out of 42 patients (12\%) had marginal flap necrosis and because of this the flap separation got delayed to more than 4 weeks. All other patients underwent flap separation around 3 weeks. In all 42 patients external fixator (Fig. 1) was used for immobilisation instead of POP cast. We did not encounter any pin site infection (Fig. 2). 6 patients had pressure sore in the heal area of donor leg, (Table 2).

\begin{tabular}{|c|c|c|}
\hline Sl. No. & Particulars & No. \\
\hline 1 & Associated Vascular Injury & 8 \\
\hline 2 & Flap Necrosis & 5 \\
\hline 3 & Pressure Sore & 5 \\
\hline 4 & Pin Site Infection & 0 \\
\hline Table 2. Description of Complications associated with \\
Cross-Leg Flap/Immobilisation \\
\hline
\end{tabular}

All patients tolerated external fixation very well. Assessment of flap vascularity was easier and fixator was adjusted in all patients as and when pedicle kinking or stretching was encountered.

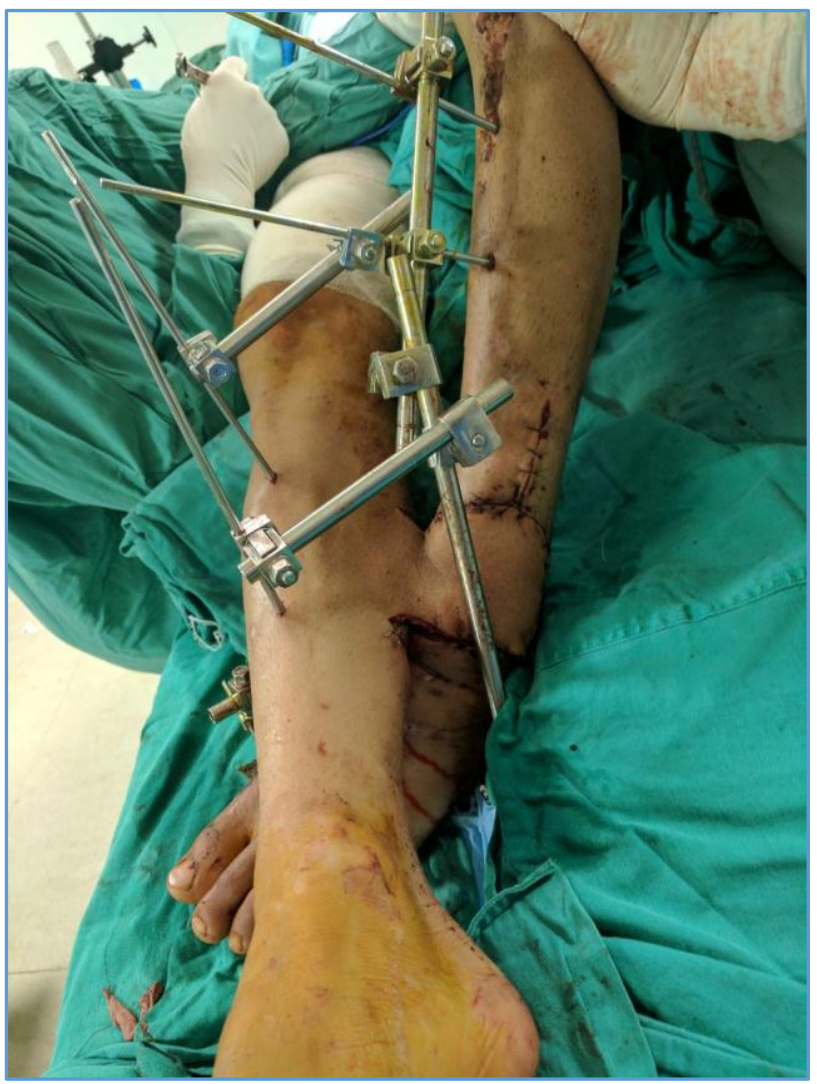

Figure 1. Cross-Leg Flap with Immobilisation using External Fixator

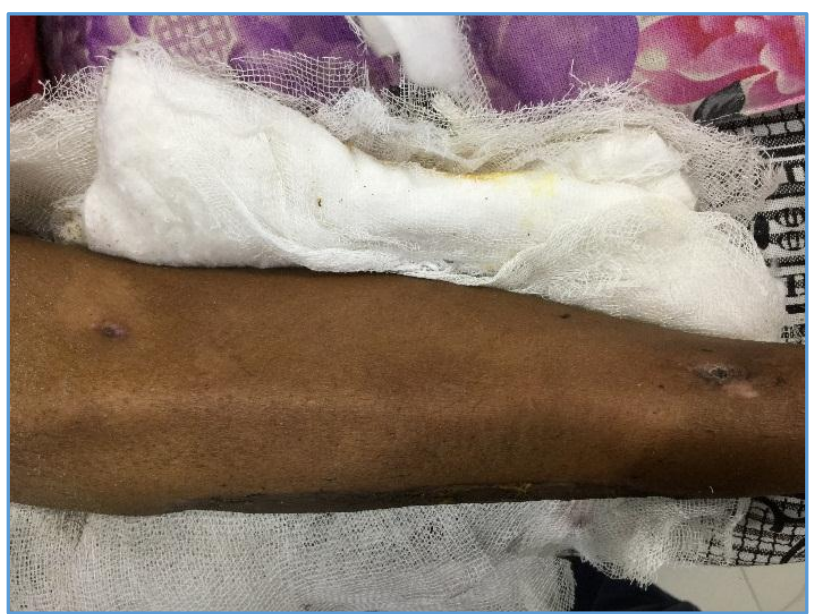

Figure 2. No Pin Site Infection

\section{DISCUSSION}

Complex injuries involving distal third of leg have always been a reconstructive challenge.[5] Unlike injuries involving proximal $2 / 3^{\text {rd }}$, distal third leg and ankle pose a tough challenge because of paucity of available tissues. Associated bony fractures with or without bone loss, exposed tendons/neurovascular structures or exposed hardware, further complicate the injury. As per the reconstructive ladder, loco regional flaps become the first reconstructive option followed by free flaps.[6] Locoregional flaps cannot be considered in case the injury is extensive and leaves no remnant skin for reconstruction. On the other hand free flaps need technical expertise, microvascular facility, good recipient vessel and good general condition of the patient to tolerate long surgery. All these pre-requisites may be difficult 
to meet and in such non-reconstructable wounds, cross-leg flap becomes a saviour. Cross-leg flap is a safe, technically easy, less time consuming option and has stood the test of time ever since its first description by Hamilton in 1854 and having been further standardised by Stark.[7] With Ponten introducing the concept of fasciocutaneous flaps in 1983, the cross-leg flap underwent further refinement and width-to-

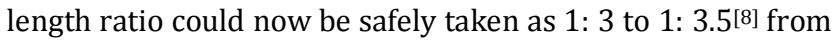
the initial length breadth ratio of $1: 1$. With the advent of perforator flaps the plastic surgeon has liberty of further increasing the length of the flap by identifying a known perforator in the flap.[9] The cross-leg flaps have evolved from being random pattern flaps to axial pattern fasciocutaneous flap based on perforators of posterior tibial artery.

In this study, all patients had wounds secondary to road traffic accidents. Associated vascular injury was seen in patients involved in 4-wheeler accidents. Majority of the patients were males (36) and in middle-age group, findings were consistent with other studies.[10],[11],[12] Lower limb trauma, more so if involving high velocity has high chances of vascular injury along with fracture of tibia/ fibula.[13],[14] There were 8 cases of vascular injury in this study. We had 100 percent coverage in all cases, despite marginal necrosis of flap in $5(12 \%)$ cases. Morris et al in their study had also reported success rate of $94 \%$ in patients undergoing conventional cross-leg flap.[15] In contrast as per study by Wells et all, free flap was able to provide stable long-term coverage in patients with Type IIIB fractures in only $78 \%$ cases.[16]

External fixator had to be adjusted in the ward in all patients. This is an added advantage of using external fixation as means of immobilisation. Flap was easily accessible and some degree of mobility of proximal joints was also permissible. There was no incidence of pin site infection at the donor leg. 6 patients developed pressure sore over heel area of donor leg. This is one drawback of using cross-leg flap and this aspect should be taken care of while planning crossleg flap. All flaps were separated around 3 weeks' time, except for in cases where there was marginal flap necrosis.

In this study, cross-leg flap had advantages of being less time consuming, technically easy and workhorse flap that comes to rescue when all other options of reconstruction have exhausted. The large amount of skin available with cross-leg flap is an added advantage for future bone grafting or fixation with plates. The fact that it needs 3 weeks of immobilisation is a big drawback and that makes it saviour flap than being a gold standard flap. External fixation as mode of immobilisation is a far better option than POP and we recommend it for all cases of cross-leg flap.

\section{CONCLUSION}

In the era of microvascualr surgery and supermicrosurgery, cross-leg flap has taken a back seat, but it surely is a saviour and acts as a lifeboat in situations where plastic surgeons encounter an unreconstructable wounds. Over the years, immobilisation has been an issue with cross-leg flap. We recommend use of external fixator in all cases of cross-leg flap.

\section{REFERENCES}

[1] Wettstein R, Schurch R, Banic A, et al. Review of 197 consecutive free flap in the lower extremity. Journal of Plastic, Reconstructive And Aesthetic Surgery 2008;61(7):772-6.

[2] Ciofu RN, Zamfirescu DG, Popescu SA, et al. Reverse sural flap for ankle and heel soft tissues reconstruction. J Med Life 2017;10(1):94-8.

[3] Touam C, Rostoucher P, Bhatia A, et al. Comparative study of two series of distally based fascio-cutaneous flaps for coverage of lower one- fourth of the leg, the ankle and the foot. Plast Recontr Surg 2001;107(2):383-92.

[4] Tajsic N, Winkel R, Husum H. Distally based perforator flaps for reconstruction of post-traumatic defects of the lower leg and foot. A review of the anatomy and clinical outcomes. Injury 2014;45(3):469-77.

[5] Taylor GI, Townsend P, Corlett R. Superiority of the deep circumflex iliac vessels as the supply for free groin flaps: clinical work. Plastic and Reconstructive Surgery 1979;64(6):745-59.

[6] Shoeib MA. Cross-leg flap: its reliability and outcome. Modern Plastic Surgery 2013;3(1) 9-14.

[7] Stark RB. The Cross-leg flap procedure. Plastic and Reconstructive Surgery 1952;9(3):173-204.

[8] Ponten B. The fasciocutaneous flap. Its use in soft tissue defects of lower leg. British Journal of Plastic Surgery 1981;34(2):215-20.

[9] Kamath BJ, Varghese T, Bhardwaj P. Tips and techniques: a modified cross leg flap for large triangular defects of the foot and ankle. Foot Ankle J 2008;1(8):5.

[10] McCall BP, Horwitz IB. An assessment and quantification of the rates, costs and risk factors of occupational amputations: analysis of Kentucky workers' compensation claims, 1994-2003. Am J Ind Med 2006;49(12):1031-8.

[11] Olson DK, Gerberich SG. Traumatic amputations in the workplace. J Occup Med 1986;28(7):480-5.

[12] Pozo JL, Powell B, Andrews BG, et al. The timing of amputation for lower limb trauma. J Bone Joint Surg Br 1990;72(2):288-92.

[13] Rozycki GS, Tremblay LN, Feliciano DV, et al. Blunt vascular trauma in the extremity: diagnosis, management and outcome. J Trauma 2003;55(5):81424.

[14] Alexander JJ, Piotrowski JJ, Graham D, et al. Outcome of complex vascular and orthopedic injuries of the lower extremity. Am J Surg 1991;162(2):111-6.

[15] Morris AM, Buchan AC. The place of the cross-leg flap in reconstructive surgery of the lower leg and foot: a review of 165 cases. Br J Plast Surg 1978;31(2):13842.

[16] Wells MD, Bowen CV, Manktelow RT, et al. Lower extremity free flaps: a review. Can J Surg 1996;39 (3):233-9. 